\title{
Clinical impact of estradiol/testosterone ratio in patients with acute ischemic stroke
}

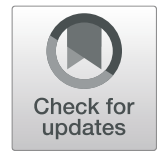

\author{
Jung-Won Choi ${ }^{1+}$, In Woo Ryoo ${ }^{2+}$, Jun Yeong Hong ${ }^{2}$, Kyung-Yul Lee ${ }^{3}$, Hyo Suk Nam³, Won Chan Kim', \\ Seung-Hun Oh', Jaeku Kang ${ }^{4}$, Hoi Young Lee ${ }^{4}$, Sang-Jun $\mathrm{Na}^{2}$, Ji Hoe Heo ${ }^{3}$ and Kee Ook Lee ${ }^{1,4^{*}}$
}

\begin{abstract}
Background: Sex hormones may be associated with a higher incidence of ischemic stroke or stroke-related events. In observational studies, lower testosterone concentrations are associated with infirmity, vascular disease, and adverse cardiovascular risk factors. Currently, female sexual hormones are considered neuroprotective agents. The purpose of this study was to assess the role of sex hormones and the ratio of estradiol/testosterone (E/T) in patients with acute ischemic stroke (AIS).
\end{abstract}

Methods: Between January 2011 and December 2016, 146 male patients with AIS and 152 age- and sex-matched control subjects were included in this study. Sex hormones, including estradiol, progesterone, and testosterone, were evaluated in the AIS patient and control groups. We analyzed the clinical and physiological levels of sex hormones and hormone ratios in these patients.

Results: The $E / T$ ratio was significantly elevated among patients in the stroke group compared to those in the control group $(P=0.001)$. Categorization of data into tertiles revealed that patients with the highest $E / T$ ratio were more likely to have AIS [odds ratio (OR) 3.084; 95\% Confidence interval $(\mathrm{Cl}): 1.616-5.886 ; P<0.001)$ compared with those in the first tertile. The $E / T$ ratio was also an independent unfavorable outcome predictor with an adjusted OR of 1.167 (95\% Cl: 1.053-1.294; $P=0.003$ ).

Conclusions: These findings support the hypothesis that increased estradiol and reduced testosterone levels are associated with AIS in men.

Keywords: Sex hormones, estradiol/testosterone ratio, Acute ischemic stroke, Functional outcome, Men

\section{Background}

Sex hormones act on the brain via both genomic and non-genomic receptors [1]. Previous preclinical evidence had shown that sex hormones play an important neuroprotective role following acute ischemic stroke (AIS) and other acute central nervous system conditions such as spinal cord and traumatic brain injuries [2]. Sex

\footnotetext{
* Correspondence: niceiatros@cha.ac.kr

†Jung-Won Choi and In Woo Ryoo contributed equally to this work.

'Department of Neurology, CHA Bundang Medical Center, CHA University, 59, Yatap-ro, Bundang-gu, Gyunggi-do 13496 Seongnam, Republic of Korea ${ }^{4}$ Myunggok Medical Research Institute, Konyang University College of Medicine, Daejeon, Korea

Full list of author information is available at the end of the article
}

hormones exert their effects directly on neuronal death pathways, and indirectly by modulating the immune system. The effects of these hormones on stroke outcomes are dose-dependent and are further associated with the patient's age [3]. Age has been linked to the prediction of cardio-metabolic risk. Sex hormones play multiple roles in the development of cardiovascular disease [4]. There are similarities and differences in sex hormones between males and females. Aging has a significant impact on estrogen and androgen levels in both sexes. In particular, while estrogen levels decrease drastically only in post-menopausal women, androgen levels gradually

(c) The Author(s). 2021 Open Access This article is licensed under a Creative Commons Attribution 4.0 International License, which permits use, sharing, adaptation, distribution and reproduction in any medium or format, as long as you give appropriate credit to the original author(s) and the source, provide a link to the Creative Commons licence, and indicate if changes were made. The images or other third party material in this article are included in the article's Creative Commons licence, unless indicated otherwise in a credit line to the material. If material is not included in the article's Creative Commons licence and your intended use is not permitted by statutory regulation or exceeds the permitted use, you will need to obtain permission directly from the copyright holder. To view a copy of this licence, visit http://creativecommons.org/licenses/by/4.0/ The Creative Commons Public Domain Dedication waiver (http://creativecommons.org/publicdomain/zero/1.0/) applies to the data made available in this article, unless otherwise stated in a credit line to the data. 
begin to decrease around 30 years of age in both sexes [5-7].

Interestingly, both clinical and experimental evidence suggest that androgen levels drop after ischemic stroke. This raises the question of whether ischemia-induced reduction in androgen levels may be as important as the steady levels of hormones prior to the insult. Some recent bench studies have revealed conflicting data and indicate that androgens can either prevent or exacerbate ischemic damage [8].

The classical endogenous and exogenous sex hormones (estrogen, testosterone, and progesterone) have profound effects on stroke incidence, risk factors, and various outcomes. Few studies have examined the direct or indirect effects of sex hormones in the treatment of ischemic stroke [9-11]. Although the available evidence supports the hypothesis that sex hormones may be associated with the pathophysiology of AIS, it remains to be determined whether these hormones affect the acute stage of the condition. The goal of this study was to (1) determine the physiological levels of the principal sex hormones in AIS; (2) investigate the relationship between the possible sex hormone ratio including estradiol/testosterone $(\mathrm{E} / \mathrm{T})$ ratio, estradiol/free testosterone (E/free T) ratio, and AIS; and (3) investigate the association of sex hormones and these ratios with functional outcomes after stroke.

\section{Methods}

\section{Study population}

The AIS patient group consisted of 146 consecutively enrolled male patients who had been admitted within 48 hours of the onset of symptoms to our neurology department from January 2011 to December 2016. The control group consisted of 152 age-matched neurologically healthy males without any recent history of stroke or other thrombotic events. The control participants were recruited from the outpatient clinic of our hospital during their scheduled health examinations. This study was conducted according to the guidelines of the Declaration of Helsinki and approved by the institutional human research ethical committee (IRB approval no. 2011004). Informed consent was obtained from all participants.

\section{Risk factor assessment}

We assessed the vascular risk factors including atrial fibrillation, cardiovascular disease (such as coronary heart disease, heart failure, and peripheral arterial disease), hypertension (HTN), diabetes mellitus (DM), hyperlipidemia, chronic kidney disease (CKD), and current smoking and alcohol drinking habits, in all participants. HTN was diagnosed when a patient demonstrated systolic blood pressure $(\mathrm{SBP}) \geq 140 \mathrm{mmHg}$, diastolic blood pressure $(\mathrm{DBP}) \geq 90 \mathrm{mmHg}$, or was receiving antihypertensive treatment. Diabetes was diagnosed when a patient had fasting plasma glucose level $\geq 7.0 \mathrm{mmol} / \mathrm{L}$, hemoglobin A1c $(\mathrm{HbA} 1 \mathrm{c}) \geq 6.5 \%$, or had been receiving oral hypoglycemic agents or insulin [12]. We also determined serum levels of total cholesterol, high-density lipoprotein (HDL) cholesterol, low-density lipoprotein (LDL) cholesterol, triglycerides (TG), and estimated glomerular filtration rate (eGFR). Body mass index (BMI) was determined as the measured weight in kilograms divided by the measured height in meters squared. Hyperlipidemia was diagnosed as total cholesterol level > $6.21 \mathrm{mmol} / \mathrm{L}$, LDL cholesterol $>4.14 \mathrm{mmol} /$ $\mathrm{L}$, or in patients receiving lipid-lowering medication. We did not include patients with severe hepatic dysfunctions (alanine aminotransferase or aspartate aminotransferase levels $>2$ times the upper limit of normal value), renal dysfunction (serum creatinine $>141.4 \mu \mathrm{mol} / \mathrm{L}$ ), recent history of infection, malignancy, previous history of peripheral vascular occlusive disease, autoimmune disease, or any other neurological disorders.

\section{Assessment of stroke severity and outcomes}

All patients with AIS underwent brain magnetic resonance imaging (MRI) and angiographic studies (MR angiography, computerized tomography angiography, or conventional cerebral angiography). The severity of initial neurological deficits was assessed using the National Institutes of Health Stroke Scale (NIHSS). Functional neurological outcomes were assessed using the modified Rankin Scale (mRS) at discharge. Unfavorable outcomes were defined as $\mathrm{mRS}$ score $>2$. Etiological stroke subtypes were determined according to the Trial of ORG 10,172 in Acute Stroke Treatment classification system [13].

\section{Data collection and laboratory examinations}

All blood samples were obtained prior to treatment (with an anticoagulant and/or antiplatelet agent). Serum specimens were centrifuged, frozen within $2 \mathrm{~h}$ of collection, and stored at $-80^{\circ} \mathrm{C}$ until analyzed. The following concentrations of components were measured using the methods specified by the manufacturer: glucose, total cholesterol, HDL cholesterol, LDL cholesterol, TG, creatinine, uric acid, and HbA1c. Plasma sex hormone levels were also determined at the hospital laboratory using a biochemical analyzer (COBAS e 411 analyzer, Roche, Mannheim, Germany). E/T and E/free $\mathrm{T}$ ratios were defined as the ratio of estradiol to total testosterone and the ratio of estradiol to free testosterone, respectively.

\section{Statistical analyses}

Statistical analyses were performed using SPSS (version 23.0; IBM SPSS Statistics, Armonk, NY, USA). Student's 
$t$-test or the Mann-Whitney $U$ test was used to compare continuous variables between the patient and control groups. The Chi-square or Fisher's exact test was used to compare categorical variables. Values were expressed as mean \pm standard deviation or number (percentage), as appropriate. Bivariate correlations between sex hormones and other parameters were compared using Pearson's correlation test. Logistic regression analysis was used to determine the relationship between risk factors and AIS. The relation of risk factors with unfavorable functional outcomes (assessed by "at discharge" mRS score) was also investigated with the use of logistic regression models. After univariate analyses, odds ratios (ORs) with $95 \%$ confidence intervals (CIs) were calculated using multivariate logistic regression. The goodness of fit of this model was assessed using the Hosmer and Lemeshow chi-squared statistic. All statistical tests were two-sided, and $P<0.05$ was considered statistically significant.

\section{Results}

Clinical and biochemical baseline demographic characteristics of the study participants are summarized in Table 1. A total of 146 patients with AIS were matched to 152 participants without the condition. The levels of SBP, DBP, total cholesterol, and TG were significantly higher, while the eGFR was significantly lower in the AIS group than in the control group. There were no differences between the AIS and control groups in BMI, DM, smoking, alcohol consumption, hyperlipidemia, HDL cholesterol, LDL cholesterol, and HbA1c. There were significant differences between the two groups in the percentage of HTN, cardiovascular disease, atrial fibrillation, and CKD. In addition, the characteristics of sex hormones are also presented in Table 1. There were no significant differences in the levels of estradiol, total testosterone, free testosterone, progesterone, and $17-\mathrm{OH}$ progesterone between the groups (Table 1). However, the two groups differed significantly in the $\mathrm{E} / \mathrm{T}$ ratio.

All participants were categorized into tertiles according to the $\mathrm{E} / \mathrm{T}$ ratio. When the baseline demographic and clinical characteristics of the participants were examined, there were significant differences between the tertiles in age, prevalence of AIS, SBP, BMI, DM, and current smoking and alcohol drinking habits (Table 2). Participants with the highest tertile E/T ratio were older and had higher SBP.

The E/T ratio was associated with AIS in both crude and multivariable analyses. After adjustment for other confounding factors, multivariate logistic regression analyses found that participants with the highest $\mathrm{E} / \mathrm{T}$ ratio were more likely to have AIS (OR: 3.084; $95 \%$ CI: 1.616-5.886; $P<0.001)$ compared with those in the first tertile (Table 3 ). The adjusted OR of the highest $\mathrm{E} / \mathrm{T}$ ratio was more obvious than that of SBP (OR: 1.016; 95\% CI: 1.003-1.029; $P=0.013$ ) and HTN (OR: 1.750; 95 \% CI: $1.026-2.984 ; P=0.040)$.

Subsequently, logistic regression analyses were conducted to evaluate the risk factors related to early unfavorable outcomes (Table 4). In univariate logistic regression analyses, the $\mathrm{E} / \mathrm{T}$ ratio had a statistically significant association with early unfavorable functional outcomes $(P=0.001)$. With adjustments for confounding factors, significant variables for unfavorable outcomes were age, HTN, atrial fibrillation, "on admission" NIHSS score, stroke subtype, and estradiol level. After adjusting for all other significant outcome predictors, the $\mathrm{E} / \mathrm{T}$ ratio remained an independent unfavorable outcome predictor with an adjusted OR of 1.167 (95\% CI: 1.0531.294; $P=0.003)$. The other significant variables for early unfavorable functional outcomes were old age (OR: 1.061; 95 \% CI: $1.006-1.119 ; P=0.029$ ), and "on admission” NIHSS score (OR: 1.539; 95 \% CI: 1.267-1.871; $P<$ 0.001) (Table 4).

The E/T ratio of the patients with early unfavorable functional outcomes was significantly higher compared to those with favorable outcomes $(P<0.001)$ (Fig. 1).

\section{Discussion}

Our study demonstrated that the E/T ratio was independently associated with both AIS and poor early functional outcomes. In this study, the highest tertile of the $\mathrm{E} / \mathrm{T}$ ratio was significantly associated with AIS. Our findings suggest that the $\mathrm{E} / \mathrm{T}$ ratio may be a possible independent biological marker of AIS. Furthermore, an elevated $\mathrm{E} / \mathrm{T}$ ratio may be used to predict early unfavorable functional outcomes. To the best of our knowledge, the current study is the first to investigate the inter-relationship between the ratio of sex hormones and early functional neurological outcomes in patients with AIS.

The presence of sexual dimorphism and their function has now been supported by evidence from the various fields of genetics, epigenetics, immunology, cellular physiology, and neurosciences. These mechanisms include apoptotic signaling cascades in neurons and glia, resident microglial activation, neuroglial response to ionic imbalance, autophagy, and mitochondrial toxicity [14]. In addition, the different effects of sexual hormone levels on the disease in males and females should be considered.

Clinical trials have demonstrated that estrogen increase the stroke incidence and severity in elderly women [2]. There is also evidence that estrogen therapy may increase thrombotic conditions and the risk of stroke. This suggests that hormones affect not only the brain, but also the coagulation system [15]. Similar 
Table 1 Distribution of demographic and clinical characteristics among acute ischemic stroke patients and controls

\begin{tabular}{|c|c|c|c|}
\hline & AIS $(n=146)$ & Control $(n=152)$ & $P$-value \\
\hline Age, years & $70.62 \pm 10.67$ & $70.51 \pm 10.49$ & 0.929 \\
\hline Systolic blood pressure, $\mathrm{mmHg}$ & $147.12 \pm 24.20$ & $134.16 \pm 22.60$ & $<0.001$ \\
\hline Diastolic blood pressure, $\mathrm{mmHg}$ & $83.40 \pm 19.18$ & $75.32 \pm 14.10$ & $<0.001$ \\
\hline Height, m & $1.67 \pm 0.07$ & $1.64 \pm 0.09$ & 0.001 \\
\hline Weight, kg & $65.80 \pm 8.98$ & $64.21 \pm 10.72$ & 0.167 \\
\hline Body mass index, $\mathrm{kg} / \mathrm{m}^{2}$ & $23.55 \pm 2.88$ & $23.84 \pm 3.27$ & 0.413 \\
\hline Hypertension & $77(52.7)$ & $58(38.2)$ & 0.014 \\
\hline Diabetes mellitus & $39(26.7)$ & $28(18.4)$ & 0.097 \\
\hline Smoking, current & $46(31.5)$ & $34(22.4)$ & 0.089 \\
\hline Alcohol, current & $57(39.0)$ & $51(33.6)$ & 0.337 \\
\hline Cardiovascular disease $^{a}$ & $32(21.9)$ & $19(12.5)$ & 0.033 \\
\hline Hyperlipidemia & $61(41.8)$ & $49(32.2)$ & 0.094 \\
\hline Atrial fibrillation & $26(17.8)$ & $14(9.2)$ & 0.040 \\
\hline CKD & $33(22.6)$ & $17(11.2)$ & 0.013 \\
\hline Total cholesterol, mmol/L & $5.24 \pm 1.10$ & $4.93 \pm 1.06$ & 0.014 \\
\hline Triglyceride, mmol/L & $1.86 \pm 0.99$ & $1.60 \pm 1.04$ & 0.032 \\
\hline HDL-cholesterol, mmol/L & $1.17 \pm 0.26$ & $1.23 \pm 0.33$ & 0.083 \\
\hline LDL-cholesterol, mmol/L & $3.35 \pm 1.04$ & $3.15 \pm 0.86$ & 0.072 \\
\hline $\mathrm{HbA} 1 \mathrm{c}, \%$ & $6.13 \pm 1.64$ & $5.83 \pm 1.17$ & 0.074 \\
\hline eGFR, mL/min/1.73 m² & $69.93 \pm 15.39$ & $74.69 \pm 13.64$ & 0.005 \\
\hline Estradiol, pmol/L & $71.63 \pm 50.45$ & $62.33 \pm 49.70$ & 0.110 \\
\hline Total testosterone, $\mathrm{nmol} / \mathrm{L}$ & $13.62 \pm 7.66$ & $15.53 \pm 10.18$ & 0.070 \\
\hline Free testosterone, $\mathrm{nmol} / \mathrm{L}$ & $0.25 \pm 0.12$ & $0.25 \pm 0.09$ & 0.827 \\
\hline Progesterone, $\mathrm{nmol} / \mathrm{L}$ & $1.71 \pm 0.70$ & $1.84 \pm 0.63$ & 0.098 \\
\hline 17-OH progesterone, $\mathrm{nmol} / \mathrm{L}$ & $4.91 \pm 1.84$ & $4.96 \pm 2.09$ & 0.809 \\
\hline $\mathrm{E} / \mathrm{T}$ ratio & $6.75 \pm 5.97$ & $4.72 \pm 4.38$ & 0.001 \\
\hline E/free T ratio & $366.43 \pm 342.95$ & $291.50 \pm 332.19$ & 0.056 \\
\hline
\end{tabular}

Data are expressed as the mean \pm SD, number (\%)

AIS acute ischemic stroke, CKD chronic kidney disease, $H D L$ high-density lipoprotein, $L D L$ low-density lipoprotein, eGFR estimated glomerular filtration rate, E/T ratio estradiol-to-testosterone ratio, E/free $T$ ratio estradiol-to-free testosterone ratio

${ }^{a}$ Cardiovascular disease includes coronary heart disease, heart failure, or peripheral arterial disease

trends were also observed in experimental stroke models. When administered to aged female rodents, estrogen paradoxically increased infarct volume after ischemic stroke [16]. These neurotoxic effects may be associated with a decrease in the utilization of insulinlike growth factor 1, a neuroprotective agent that decreases with age and is downregulated by estrogen treatment [17]. However, these studies were conducted only in women. Furthermore, the effects of estrogen therapy duration or dose on the experimental results were unclear [18].

Estradiol is the most potent endogenous estrogen. Estradiol is the main female sex hormone and plays an important role in the promotion of secondary sexual characteristics, and development of the reproductive system and breast tissue [10, 19]. Estradiol affects the brain through estrogen receptors (ER), most of which act through ER $\alpha$ of endothelium and smooth muscle cell, increase the transcription of pro-survival gene, and decrease pro-apoptotic gene [20-22]. Estradiol increases activation of extracellular signal-regulated kinase, which is involved in overall cell survival, inhibits the proapoptotic c-Jun N-terminal kinase pathway, and increases endothelial nitric oxide synthase and prostacyclin synthase, leading to vasodilation [20-23]. It is also known that estradiol may increase endothelial progenitor cell proliferation, which promotes angiogenesis [20]. Considering these mechanisms, estradiol is thought to have a neuroprotective effect basically, but some clinical studies have drawn different results from hypothesis. One study obtained blood samples from 302 postmenopausal women hospitalized with AIS and found an 
Table 2 Participant characteristics according to the estradiol-to-testosterone ratio tertile

\begin{tabular}{|c|c|c|c|c|}
\hline & Tertiles of estr & sterone ratio & & $P-$ \\
\hline & 1 st $(<2.33)$ & 2nd (2.37-6.39) & $3 \mathrm{rd}(6.53<)$ & \\
\hline & $n=99$ & $n=100$ & $n=99$ & \\
\hline Age, years & $69.42 \pm 11.05$ & $68.15 \pm 10.73$ & $74.13 \pm 8.91$ & $<0.001$ \\
\hline Prevalence of AIS & $33(33.3)$ & $50(50.0)$ & $63(63.6)$ & $<0.001$ \\
\hline Systolic blood pressure, mmHg & $134.84 \pm 23.38$ & $142.56 \pm 25.18$ & $144.11 \pm 23.33$ & 0.015 \\
\hline Diastolic blood pressure, $\mathrm{mmHg}$ & $76.24 \pm 15.67$ & $80.70 \pm 18.85$ & $80.88 \pm 16.79$ & 0.100 \\
\hline Body mass index, $\mathrm{kg} / \mathrm{m}^{2}$ & $24.13 \pm 3.12$ & $23.00 \pm 3.22$ & $23.97 \pm 2.80$ & 0.019 \\
\hline Hypertension & $49(49.5)$ & $44(44.0)$ & $42(42.4)$ & 0.586 \\
\hline Diabetes mellitus & $13(13.1)$ & $32(32.0)$ & $22(22.2)$ & 0.006 \\
\hline Smoking, current & $25(25.3)$ & $19(19.0)$ & $36(36.4)$ & 0.020 \\
\hline Alcohol, current & $32(32.3)$ & $30(30.0)$ & $46(46.5)$ & 0.032 \\
\hline Cardiovascular disease $^{a}$ & $13(13.1)$ & $24(24.0)$ & $14(14.1)$ & 0.090 \\
\hline Hyperlipidemia & $33(33.3)$ & $41(41.0)$ & $36(36.4)$ & 0.553 \\
\hline Atrial fibrillation & $15(15.2)$ & $8(8.0)$ & $17(17.2)$ & 0.143 \\
\hline CKD & $14(14.1)$ & $21(21.0)$ & $15(15.2)$ & 0.388 \\
\hline Total cholesterol, mmol/L & $4.94 \pm 1.14$ & $5.02 \pm 1.07$ & $5.29 \pm 1.03$ & 0.060 \\
\hline Triglyceride, mmol/L & $1.70 \pm 1.02$ & $1.63 \pm 0.95$ & $1.85 \pm 1.08$ & 0.307 \\
\hline HDL-cholesterol, mmol/L & $1.21 \pm 0.30$ & $1.15 \pm 0.31$ & $1.24 \pm 0.29$ & 0.107 \\
\hline LDL-cholesterol, mmol/L & $3.12 \pm 0.96$ & $3.26 \pm 0.92$ & $3.36 \pm 0.98$ & 0.202 \\
\hline $\mathrm{HbA} 1 \mathrm{c}, \%$ & $5.72 \pm 1.00$ & $6.11 \pm 1.77$ & $6.10 \pm 1.38$ & 0.089 \\
\hline $\mathrm{eGFR}, \mathrm{mL} / \mathrm{min} / 1.73 \mathrm{~m}^{2}$ & $74.64 \pm 14.27$ & $70.44 \pm 14.16$ & $72.02 \pm 15.45$ & 0.125 \\
\hline E2 (estradiol), pmol/L & $26.69 \pm 19.96$ & $61.70 \pm 36.44$ & $112.32 \pm 46.40$ & $<0.001$ \\
\hline Total testosterone, $\mathrm{nmol} / \mathrm{L}$ & $16.57 \pm 10.87$ & $16.09 \pm 8.93$ & $11.11 \pm 5.68$ & $<0.001$ \\
\hline Free testosterone, $\mathrm{nmol} / \mathrm{L}$ & $0.24 \pm 0.08$ & $0.26 \pm 0.10$ & $0.24 \pm 0.14$ & 0.498 \\
\hline Progesterone, $\mathrm{nmol} / \mathrm{L}$ & $1.61 \pm 0.54$ & $1.91 \pm 0.74$ & $1.81 \pm 0.66$ & 0.004 \\
\hline 17-OH progesterone, $\mathrm{nmol} / \mathrm{L}$ & $4.60 \pm 1.81$ & $5.33 \pm 1.98$ & $4.87 \pm 2.05$ & 0.030 \\
\hline
\end{tabular}

Data are expressed as the mean $\pm S D$, number (\%)

AIS acute ischemic stroke, CKD chronic kidney disease, HDL high-density lipoprotein, LDL low-density lipoprotein, eGFR estimated glomerular filtration rate ${ }^{a}$ Cardiovascular disease includes coronary heart disease, heart failure, or peripheral arterial disease

association between higher estradiol levels and stroke severity, 1-month mortality, and poor functional outcomes [24]. The study reported that estradiol levels remained independently associated with the aforementioned parameters, even after correction of confounders. The study concluded that stroke itself may elevate estradiol levels as an endogenous protective mechanism. Another study reported that higher circulating estradiol levels in late post-menopausal women were associated with higher mortality, independent of age and multiple confounders [25]. This study also suggested that the prothrombotic effects of estradiol may explain the high rate of thrombotic events observed in post-menopausal women. Lee et al. suggested that post-menopausal women with high endogenous free estradiol levels had 2.3-fold greater odds of stroke, independent of age [26]. However, these prospective studies can only reveal associations, not causality [24-26]. Nevertheless, higher levels of estradiol may be a marker of cerebrovascular disease and could help in identification of patients with AIS who are at risk of worsening unfavorable functional outcomes and mortality [24, 25].

Related studies of testosterone levels provide conflicting data on the true effects of the hormone on visceral adiposity, independent of other sex hormones. High serum testosterone is associated with reduced subcutaneous and increased abdominal adiposity in women, while low testosterone is associated with the same effect in men [27-29]. In older men, sex hormone levels do not decrease as rapidly as in menopausal women however, testosterone levels decline steadily with age [30].These declining testosterone levels have been reported to be associated with elevated visceral adiposity in older men [31]. This may play a role in increased risk of cardiovascular diseases in aging men. Low testosterone levels are associated with increased systemic 
Table 3 Univariate and multivariate analyses of risk factors for acute cerebral infarction

\begin{tabular}{|c|c|c|c|c|c|c|}
\hline & \multicolumn{3}{|c|}{ Univariate analysis } & \multicolumn{3}{|c|}{ Multivariate analysis } \\
\hline & OR & $95 \% \mathrm{Cl}$ & $P$-value & OR & $95 \% \mathrm{Cl}$ & $P$-value \\
\hline Systolic blood pressure & 1.024 & $1.014-1.035$ & $<0.001$ & 1.016 & $1.003-1.029$ & 0.013 \\
\hline Diastolic blood pressure & 1.031 & $1.015-1.046$ & $<0.001$ & 1.015 & $0.998-1.033$ & 0.085 \\
\hline Body mass index & 0.969 & $0.900-1.044$ & 0.412 & & & \\
\hline Hypertension & 1.809 & $1.140-2.868$ & 0.012 & 1.750 & $1.026-2.984$ & 0.040 \\
\hline Diabetes mellitus & 1.614 & $0.931-2.798$ & 0.088 & & & \\
\hline Smoking, current & 1.596 & $0.952-2.678$ & 0.076 & & & \\
\hline Alcohol, current & 1.268 & $0.790-2.036$ & 0.325 & & & \\
\hline Cardiovascular disease $^{a}$ & 1.965 & $1.057-3.654$ & 0.033 & 1.374 & $0.660-2.863$ & 0.396 \\
\hline Hyperlipidemia & 1.509 & $0.940-2.421$ & 0.089 & & & \\
\hline Atrial fibrillation & 2.136 & $1.067-4.276$ & 0.032 & 1.998 & $0.923-4.326$ & 0.079 \\
\hline CKD & 2.319 & $1.227-4.382$ & 0.010 & 1.709 & $0.648-4.511$ & 0.279 \\
\hline Total cholesterol & 1.305 & $1.053-1.618$ & 0.015 & 1.144 & $0.883-1.480$ & 0.308 \\
\hline Triglyceride & 1.288 & $1.018-1.631$ & 0.035 & 1.313 & $0.997-1.728$ & 0.053 \\
\hline HDL-cholesterol & 0.510 & $0.237-1.098$ & 0.085 & & & \\
\hline LDL-cholesterol & 1.248 & $0.980-1.589$ & 0.072 & & & \\
\hline $\mathrm{HbA1c}$ & 1.164 & $0.984-1.377$ & 0.077 & & & \\
\hline eGFR & 0.977 & $0.962-0.993$ & 0.006 & 0.989 & $0.965-1.014$ & 0.397 \\
\hline E2 (estradiol) & 1.004 & $0.999-1.008$ & 0.110 & & & \\
\hline Total testosterone & 0.976 & $0.950-1.002$ & 0.075 & & & \\
\hline Free testosterone & 0.791 & 0.099-6.339 & 0.825 & & & \\
\hline Progesterone & 0.746 & $0.526-1.057$ & 0.099 & & & \\
\hline 17-OH progesterone & 0.986 & 0.878-1.107 & 0.808 & & & \\
\hline \multicolumn{7}{|l|}{$E / T$ ratio } \\
\hline 1st tertile & \multicolumn{3}{|c|}{ Reference } & \multicolumn{3}{|c|}{ Reference } \\
\hline 2nd tertile & 2.000 & $1.128-3.547$ & 0.018 & 1.813 & $0.955-3.442$ & 0.069 \\
\hline 3rd tertile & 3.500 & $1.950-6.283$ & $<0.001$ & 3.084 & $1.616-5.886$ & 0.001 \\
\hline
\end{tabular}

$O R$ odds ratio, $C l$ confidence interval, CKD chronic kidney disease, HDL high-density lipoprotein, $L D L$ low-density lipoprotein, eGFR estimated glomerular filtration rate, $E / T$ ratio estradiol-to-testosterone ratio

${ }^{a}$ Cardiovascular disease includes coronary heart disease, heart failure, or peripheral arterial disease

inflammation [32] and endothelial dysfunction [33], both of which contribute to atherosclerosis. Epidemiological studies have shown that low testosterone levels independently predict the atherosclerosis development [34, 35]. Some meta-analyses have demonstrated that low testosterone levels increase the risk of major cardiovascular diseases as well as mortality $[36,37]$. While many studies have reported the association between mortality in men and low circulating levels of testosterone [38], few have investigated the association between testosterone and the incidence of AIS. Levels of testosterone fluctuate throughout life in males. Increased levels observed in young men and decreased levels of the hormone in older men have been shown to increase the risk of ischemic stroke $[39,40]$. It has also been hypothesized that aged men have reduced functional outcomes after AIS as a result of the progressive decreased testosterone, in contrast to the neuroprotective effect observed in the female brain [41]. Although the effects of estradiol and testosterone vary greatly depending on age and sex, it is reported that in elderly men, as total testosterone levels decrease, the incidence of stroke increases and functional outcomes may be poor even after adjusting for existing cardiovascular risk factors [42-44]. This is probably due to the antiinflammatory and anti-oxidant effects of testosterone itself on brain endothelial cells and vascular smooth muscle cells in the pathologic state, but suggests that the balance between estradiol and testosterone may also be important $[45,46]$. Based on these results, in order to determine the impact of testosterone on the outcomes of ischemic stroke, a more robust study should be designed that considers the levels of endogenous testosterone and other sex hormones. 
Table 4 Univariate and multivariate analyses for early unfavorable outcomes

\begin{tabular}{|c|c|c|c|c|c|c|}
\hline & \multicolumn{3}{|c|}{ Univariate analysis } & \multicolumn{3}{|c|}{ Multivariate analysis } \\
\hline & OR & $95 \% \mathrm{Cl}$ & $P$-value & $\mathrm{OR}$ & $95 \% \mathrm{Cl}$ & $P$-value \\
\hline Age & 1.087 & $1.047-1.128$ & $<0.001$ & 1.061 & $1.006-1.119$ & 0.029 \\
\hline Systolic blood pressure & 0.994 & $0.981-1.008$ & 0.405 & & & \\
\hline Diastolic blood pressure & 1.001 & $0.984-1.018$ & 0.886 & & & \\
\hline Body mass index & 1.018 & $0.909-1.141$ & 0.752 & & & \\
\hline Hypertension & 1.985 & $1.024-3.848$ & 0.042 & 2.601 & $0.849-7.963$ & 0.094 \\
\hline Diabetes mellitus & 1.981 & $0.941-4.170$ & 0.072 & & & \\
\hline Smoking, current & 1.076 & $0.535-2.166$ & 0.837 & & & \\
\hline Alcohol, current & 1.328 & $0.681-2.587$ & 0.405 & & & \\
\hline Cardiovascular disease $^{a}$ & 1.646 & $0.747-3.627$ & 0.217 & & & \\
\hline Hyperlipidemia & 1.889 & $0.970-3.677$ & 0.061 & & & \\
\hline Atrial fibrillation & 2.556 & $1.054-6.194$ & 0.038 & 1.657 & $0.435-6.319$ & 0.460 \\
\hline CKD & 1.773 & $0.809-3.883$ & 0.153 & & & \\
\hline Total cholesterol & 1.001 & $0.994-1.009$ & 0.750 & & & \\
\hline Triglyceride & 0.998 & $0.994-1.001$ & 0.221 & & & \\
\hline HDL-cholesterol & 0.975 & $0.944-1.008$ & 0.134 & & & \\
\hline LDL-cholesterol & 1.003 & $0.995-1.011$ & 0.481 & & & \\
\hline $\mathrm{HbA1c}$ & 1.034 & $0.848-1.261$ & 0.742 & & & \\
\hline eGFR & 0.984 & $0.963-1.006$ & 0.148 & & & \\
\hline Admission NIHSS score & 1.682 & $1.395-2.029$ & $<0.001$ & 1.539 & $1.267-1.871$ & $<0.001$ \\
\hline \multicolumn{7}{|l|}{ Stroke subtypes } \\
\hline Large artery atherosclerosis & \multicolumn{6}{|c|}{ Reference } \\
\hline Cardioembolism & 2.177 & $0.905-5.233$ & 0.082 & 2.112 & $0.571-7.813$ & 0.263 \\
\hline Small vessel disease & 0.260 & $0.087-0.773$ & 0.015 & 0.206 & $0.034-1.237$ & 0.084 \\
\hline Unknown/undetermined causes & 0.390 & $0.145-1.047$ & 0.062 & 0.590 & $0.143-2.427$ & 0.464 \\
\hline E2 (estradiol) & 1.011 & $1.004-1.018$ & 0.002 & 1.003 & 0.993-1.014 & 0.507 \\
\hline Total testosterone & 0.961 & 0.919-1.005 & 0.080 & & & \\
\hline Free testosterone & 0.169 & $0.012-2.450$ & 0.192 & & & \\
\hline Progesterone & 1.616 & $0.988-2.642$ & 0.056 & & & \\
\hline 17-OH progesterone & 0.979 & $0.820-1.170$ & 0.815 & & & \\
\hline $\mathrm{E} / \mathrm{T}$ ratio & 1.134 & $1.052-1.221$ & 0.001 & 1.167 & $1.053-1.294$ & 0.003 \\
\hline
\end{tabular}

$O R$ odds ratio, $C l$ confidence interval, $C K D$ chronic kidney disease, HDL high-density lipoprotein, LDL low-density lipoprotein, eGFR estimated glomerular filtration rate, NIHSS National Institutes of Health Stroke Scale, E/T ratio estradiol-to-testosterone ratio

${ }^{a}$ Cardiovascular disease includes coronary heart disease, heart failure, or peripheral arterial disease

We have suggested a unique concept in this study, namely the $\mathrm{E} / \mathrm{T}$ ratio, and investigated the association between this ratio, AIS, and unfavorable functional outcomes. The novelty of this work is that it presents a new form of biomarker by combining estradiol and testosterone to quantitatively identify the influence of acute ischemic stroke. In this study, the $\mathrm{E} / \mathrm{T}$ values showed clear differences between the two groups, but the values of estradiol and testosterone did not show statistical differences. This is probably considered a problem of diagnostic values. Although not statistically significant, there were an increase in estradiol and a decrease in testosterone level in AIS group, compared with control. The estradiol and testosterone levels were affected by age and sex. This study is also meaningful in comparing estradiol and testosterone respectively in patients with AIS, but more focused suggests that using the E/T ratio can increase the diagnostic value. This study suggests that estradiol and testosterone may have clinical significance in AIS patients, but lower testosterone level compared to estradiol level is more correlated with AIS and early unfavorable functional outcome. $\mathrm{E} / \mathrm{T}$ ratio was concluded to be a useful biomarker for AIS and early unfavorable functional outcomes. The results of our 


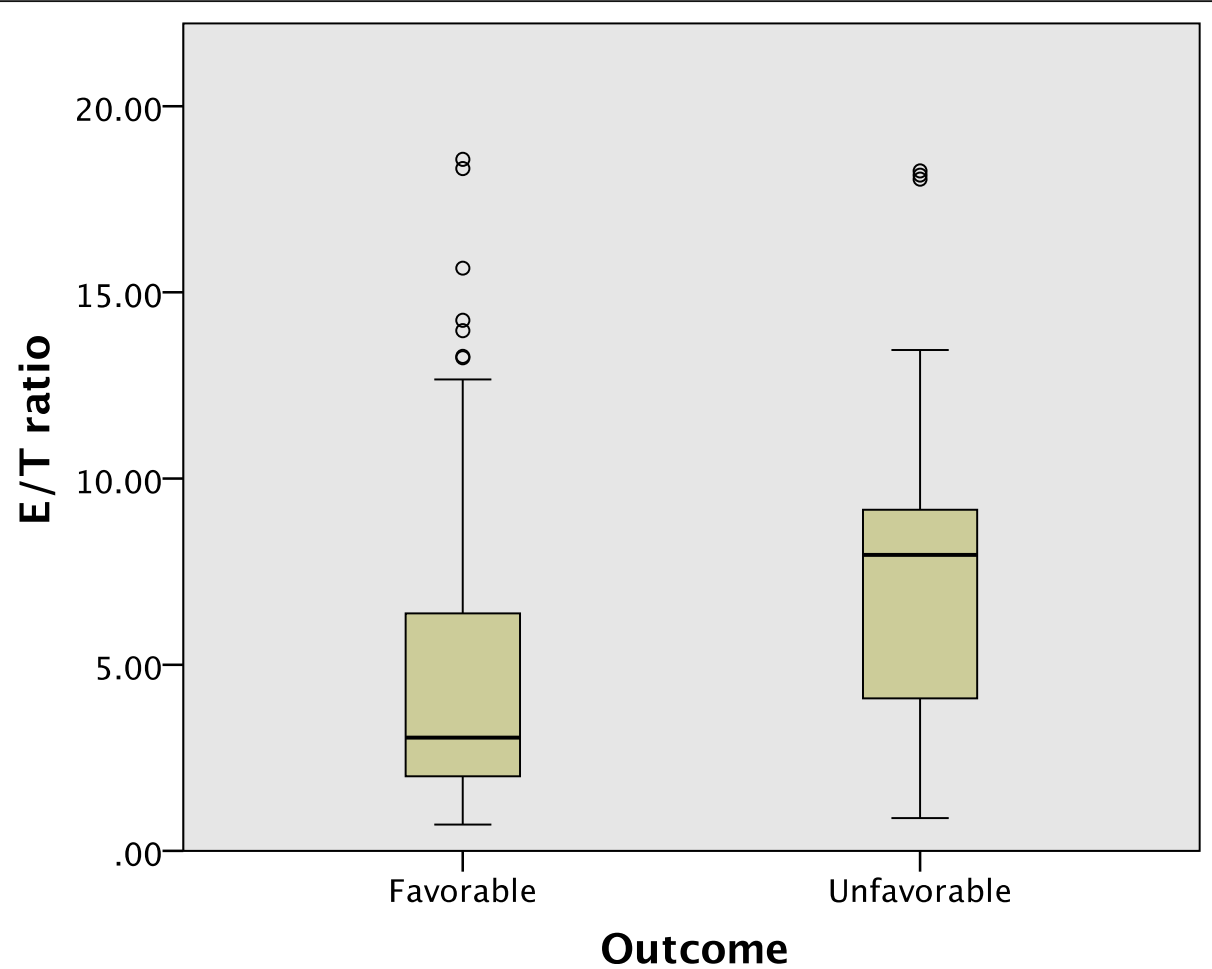

Fig. 1 Boxplot of the estradiol/testosterone (E/T) ratio according to early functional neurological outcomes

study are consistent with some previously reported observations. In a study on middle-aged men, wherein testosterone or estradiol was measured by immunoassay, higher estradiol levels were associated with cardiovascular disease [47]. In a study on elderly men, higher total testosterone using mass spectrometry was associated with a lower incidence of cardiovascular events, with similar hazard ratio in men with and without preexisting cardiovascular disease [48]. Another study in aged men using mass spectrometry for hormonal analysis found no association between testosterone and cardiovascular events, defined as myocardial infarction (MI), stroke, or cardiovascular disease-related death [49]. A recent study on elderly men reported that higher plasma testosterone is an associated biomarker for reduced risk of stroke, but not MI [44]. Another recent study reported that extremely low plasma testosterone levels were associated with a high risk of ischemic stroke in men, and that this was caused by being overweight, and HTN [50]. Testosterone was found to independently induce endothelial relaxation through secretion of endothelial nitric oxide synthase, which causes vasodilation [51]. In obese men, the reduction in these neuroprotective effects may be related to development of AIS, due to increase in blood pressure. Furthermore, the conversion of testosterone to estradiol arises in adipose tissue by aromatization, and excessive adipose tissue may reduce plasma testosterone concentrations [50, 52]. Therefore, the applicability of the E/T ratio, and the association between higher $\mathrm{E} / \mathrm{T}$ ratio and prevalence of AIS should be considered.

Several limitations should be considered for the present study. First, this was a single-center study conducted on a single race. The sample size was small for the results may not be generalizable to other demographic groups. A large-scale, multi-center external validation of the current study is necessary. Second, we primarily considered cross-sectional observational data, which may reduce accuracy. Particularly, female were excluded from this study because plasma sex hormones vary widely depending on menstruation or menopause. Such variations are also observed in men. However, not to the extent seen in women. It would be interesting to conduct a study that distinguishes the causal relationship between sex hormones and stroke in pre- and postmenopausal women. Furthermore, it would be also interesting to conduct a large-scale study comparing reproductive and elderly age for various sex hormones in stroke. Third, we did not serially measure plasma sex hormone levels, which prevented us from determining the cause and effect relationship between the hormones and AIS or other functional outcomes. We did not illustrate the longitudinal relationship between sex hormones and AIS. Fourth, the E/T ratio may be related to inflammation and short-term outcomes, which may be related to the infarct volume, but could not be measured in this 
study. MRI volumetry should be used to provide more accurate and reliable information on infarct volume. A large-scale study using this technique is warranted. Fifth, access to the proven gold standard mass spectrometry estradiol measurement technique for routine clinical use is limited. Therefore, immunoassay, as used in this study, may have resulted in inaccurate measurement of low serum concentrations of estradiol in men, which could lead to overestimation of estradiol [53]. Sixth, there was no difference in BMI between stroke and control group in this study. In univariate analysis, BMI did not show any association with AIS or early outcome, and correlation analysis also showed no correlation with estradiol or testosterone. However, in several previous studies, BMI is known to be closely related to hormone level and particularly to estradiol level in postmenopausal women. BMI has been reported to be positively correlated with estrone concentrations in older estradiol therapy users [54], and there are studies showing that serum estrogen in post-menopausal women is directly associated with BMI $[55,56]$. It is also known that elevated BMI alters the hypothalamus-pituitary-gonadal axis, hormone levels, and gametogenesis [57]. Therefore, a large scale studies including post-menopausal women are needed, considering the relationship between BMI and sex hormones. Finally, since early functional outcomes were assessed in this study, it is necessary to verify the association with long-term neurological outcomes. Despite these limitations, the results suggest that the E/T ratio may be of diagnostic and prognostic value for AIS.

\section{Conclusions}

Our study demonstrated a relationship between the E/T ratio and AIS. The E/T ratio may be a useful, noninvasive, convenient indicator that potentially predicts early unfavorable functional outcomes in male patients with AIS. Further large-scale investigations are necessary to explore the causal associations among sex hormones, $\mathrm{E} / \mathrm{T}$ ratio, AIS, and functional neurological outcomes. Estrogen and progesterone are neuroprotective and antiinflammatory hormones in various disease models of the brain, particularly in acute inflammatory conditions such as stroke. Several recent studies have revealed conflicting data and indicate that androgens can either protect against or exacerbate ischemic damage. However, it remains to be determined whether sex hormones affect the acute stage of ischemic stroke. Thus, large scale additional studies are warranted to explore the potential mechanisms underlying this association and to separately evaluate reproductive age and elderly, including female patients.

\section{Abbreviations}

AIS: Acute ischemic stroke; E/T: Estradiol/testosterone; E/free T: Estradiol/free testosterone; HTN: Hypertension; DM: Diabetes mellitus; CKD: Chronic kidney disease (CKD); SBP: Systolic blood pressure; DBP: Diastolic blood pressure; HbA1c: Hemoglobin A1c; HDL: High-density lipoprotein; LDL: Low-density lipoprotein; TG: Triglycerides; eGFR: Estimated glomerular filtration rate; BMI: Body mass index; MRI: Magnetic resonance imaging; NIHSS: National Institutes of Health Stroke Scale; mRS: Modified Rankin Scale; ORs: Odds ratios; Cls: Confidence intervals; MI: Myocardial infarction

\section{Authors' contributions}

JC and IWR equally contributed as co-first authors to this article. The twelve authors are justifiably credited with authorship, according to the authorship criteria. In detail: (1) JC: conception, design, drafting of manuscript, acquisition of data, final approval of manuscript, (2) IWR: conception, design, drafting of manuscript, acquisition of data, final approval of manuscript, (3) $\mathrm{JYH}$ : design, acquisition of data, revision of manuscript, final approval of manuscript, (4) KL: design, acquisition of data, revision of manuscript, final approval of manuscript, (5) HSN: design, acquisition of data, revision of manuscript, final approval of manuscript, (6) WCK: design, acquisition of data, interpretation of data, revision of manuscript, final approval of manuscript, (7) SO: design, acquisition of data, revision of manuscript, final approval of manuscript, (8) JK: design, acquisition of data, revision of manuscript, final approval of manuscript, (9) HYL: design, acquisition of data, revision of manuscript, final approval of manuscript, (10) SN: design, acquisition of data, revision of manuscript, final approval of manuscript, (11) $\mathrm{JHH}$ : design, acquisition of data, revision of manuscript, final approval of manuscript, (12) KOL: conception, design, acquisition of data, analysis and interpretation of data, critical revision of manuscript, final approval of manuscript.

\section{Funding}

This study was supported by a grant from the Konyang University Myunggok Research Fund, 2009.

\section{Availability of data and materials}

The datasets generated and/or analysed during the current study are available from the corresponding author on reasonable request.

\section{Ethics approval and consent to participate}

Ethical approval letter was obtained from the institutional human research ethical committee of the Konyang University College of Medicine (IRB approval no. 2011-004).

All participants/their guardians gave informed written consent before taking part in the study.

The research was performed in accordance with the Declaration of Helsinki.

\section{Consent for publication}

Not Applicable.

\section{Competing interests}

The authors declare that they have no competing interests.

\section{Author details}

'Department of Neurology, CHA Bundang Medical Center, CHA University, 59, Yatap-ro, Bundang-gu, Gyunggi-do 13496 Seongnam, Republic of Korea. ${ }^{2}$ Department of Neurology, Konyang University College of Medicine, Daejeon, Korea. ${ }^{3}$ Department of Neurology, Yonsei University College of Medicine, Seoul, Korea. ${ }^{4}$ Myunggok Medical Research Institute, Konyang University College of Medicine, Daejeon, Korea.

Received: 3 June 2020 Accepted: 19 February 2021

Published online: 26 February 2021

\section{References}

1. McEwen BS, Milner TA. Understanding the broad influence of sex hormones and sex differences in the brain. J Neurosci Res. 2017;95(1-2):24-39. doi: https://doi.org/10.1002/jnr.23809.

2. Kim T, Chelluboina B, Chokkalla AK, Vemuganti R. Age and sex differences in the pathophysiology of acute CNS injury. Neurochem Int. 2019;127:22-8. https://doi.org/10.1016/j.neuint.2019.01.0122019.01.012.

3. Spychala MS, Honarpisheh P, McCullough LD. Sex differences in neuroinflammation and neuroprotection in ischemic stroke. J Neurosci Res. 2017;95(1-2):462-71. doi:https://doi.org/10.1002/jnr.23962. 
4. Faulkner $\mathrm{J}$, Belin de Chantemele EJ. Sex hormones, aging and cardiometabolic syndrome. Biol Sex Differ. 2019;10 1:30. doi:https://doi.org/1 0.1186/s13293-019-0246-6.

5. Castelo-Branco C, Soveral I. The immune system and aging: a review. Gynecol Endocrinol. 2014;30 1:16-22. doi:https://doi.org/10.3109/09513590.2 013.8525312013 .852531$.

6. Davison SL, Bell R, Donath S, Montalto JG, Davis SR. Androgen levels in adult females: changes with age, menopause, and oophorectomy. J Clin Endocrinol Metab. 2005;90 7:3847-53. doi:https://doi.org/10.1210/jc.200502122005-0212

7. Harman SM, Metter EJ, Tobin JD, Pearson J, Blackman MR. Baltimore Longitudinal Study of A. Longitudinal effects of aging on serum total and free testosterone levels in healthy men. Baltimore Longitudinal Study of Aging. J Clin Endocrinol Metab. 2001;86(2):724-31. doi:https://doi.org/10.121 0/jcem.86.2.7219.

8. Zuo W, Zhang $\mathrm{W}$, Chen $\mathrm{NH}$. Sexual dimorphism in cerebral ischemia injury. Eur J Pharmacol. 2013;711 1-3:73-9; https://doi.org/10.1016/j.ejphar.2013.04. 0242013.04.024.

9. Bushnell CD, Reeves MJ, Zhao X, Pan W, Prvu-Bettger J, Zimmer L, et al. Sex differences in quality of life after ischemic stroke. Neurology. 2014;82 11: 922-31. doi:https://doi.org/10.1212/WNL.0000000000000208.

10. Koellhoffer EC, McCullough LD. The effects of estrogen in ischemic stroke. Transl Stroke Res. 2013;4 4:390-401. doi:https://doi.org/10.1007/s12975-0120230-5.

11. Siegel C, Turtzo C, McCullough LD. Sex differences in cerebral ischemia: possible molecular mechanisms. J Neurosci Res. 2010;88 13:2765-74. doi: https://doi.org/10.1002/jnr.22406

12. Furie KL, Kasner SE, Adams RJ, Albers GW, Bush RL, Fagan SC, et al. Guidelines for the prevention of stroke in patients with stroke or transient ischemic attack: a guideline for healthcare professionals from the american heart association/american stroke association. Stroke. 2011;42(1):227-76. doi:https://doi.org/10.1161/STR.0b013e3181 f7d043

13. Adams HP Jr, Bendixen BH, Kappelle LJ, Biller J, Love BB, Gordon DL, et al. Classification of subtype of acute ischemic stroke. Definitions for use in a multicenter clinical trial. TOAST. Trial of Org 10172 in Acute Stroke Treatment. Stroke. 1993;24 1:35-41.

14. Demarest TG, McCarthy MM. Sex differences in mitochondrial (dys)function: Implications for neuroprotection. J Bioenerg Biomembr. 2015;47 1-2:173 88; https://doi.org/10.1007/s10863-014-9583-7.

15. Laliberte F, Dea K, Duh MS, Kahler KH, Rolli M, Lefebvre P. Does the route of administration for estrogen hormone therapy impact the risk of venous thromboembolism? Estradiol transdermal system versus oral estrogen-only hormone therapy. Menopause. 2011;18 10:1052-9. doi:https://doi.org/10.1 097/gme.0b013e3182175e5c.

16. Carswell HV, Bingham D, Wallace K, Nilsen M, Graham DI, Dominiczak AF, et al. Differential effects of 17 beta-estradiol upon stroke damage in stroke prone and normotensive rats. J Cereb Blood Flow Metab. 2004;24 3:298304. doi:https://doi.org/10.1097/01.WCB.0000112322.75217.FD.

17. Selvamani A, Sohrabji F. The neurotoxic effects of estrogen on ischemic stroke in older female rats is associated with age-dependent loss of insulinlike growth factor-1. J Neurosci. 2010;30 20:6852-61. doi:https://doi.org/10.1 523/JNEUROSCI.0761-10.20102010.

18. Strom JO, Ingberg E. Impact of methodology on estrogens' effects on cerebral ischemia in rats: an updated meta-analysis. BMC Neurosci. 2014;15: 22. doi:https://doi.org/10.1186/1471-2202-15-22.

19. Duckles SP, Krause DN. Cerebrovascular effects of oestrogen: multiplicity of action. Clin Exp Pharmacol Physiol. 2007;34 8:801-8. doi:https://doi.org/1 0.1111/j.1440-1681.2007.04683.x2007.04683.x

20. Meadows KL. Ischemic stroke and select adipose-derived and sex hormones: a review. Hormones (Athens). 2018;17 2:167 - 82;https://doi. org/10.1007/s42000-018-0034-4

21. Schreihofer DA, Ma Y. Estrogen receptors and ischemic neuroprotection: who, what, where, and when? Brain Res. 2013;1514:107-22. doi:https://doi. org/10.1016/j.brainres.2013.02.0512013.02.051.

22. Scott E, Zhang QG, Wang R, Vadlamudi R, Brann D. Estrogen neuroprotection and the critical period hypothesis. Front Neuroendocrinol. 2012;33 1:85-104. doi:https://doi.org/10.1016/j.yfrne.2011.10.0012011.10.001.

23. Bramlett HM. Sex differences and the effect of hormonal therapy on ischemic brain injury. Pathophysiology. 2005;12 1:17-27. doi:https://doi.org/1 0.1016/j.pathophys.2005.02.0092005.02.009.
24. Pappa T, Vemmos K, Mantzou E, Savvari P, Stamatelopoulos K, Alevizaki M. Estradiol levels predict short-term adverse health outcomes in postmenopausal acute stroke women. Eur J Neurol. 2012;19 10:1300-4. doi: https://doi.org/10.1111/j.1468-1331.2012.03714.x2012.03714.x.

25. Maggio M, Ceda GP, Lauretani F, Bandinelli S, Ruggiero C, Guralnik JM, et al. Relationship between higher estradiol levels and 9-year mortality in older women: the Invecchiare in Chianti study. J Am Geriatr Soc. 2009;57 10: 1810-5. doi:https://doi.org/10.1111/j.1532-5415.2009.02464.x2009.02464.x.

26. Lee JS, Yaffe K, Lui LY, Cauley J, Taylor B, Browner W, et al. Prospective study of endogenous circulating estradiol and risk of stroke in older women. Arch Neurol. 2010;67 2:195-201. doi:https://doi.org/10.1001/archneurol.2009.3222 009.322.

27. Haffner SM, Karhapaa P, Mykkanen L, Laakso M. Insulin resistance, body fat distribution, and sex hormones in men. Diabetes. 1994;43 2:212-9. doi: https://doi.org/10.2337/diab.43.2.212.

28. Janssen I, Powell LH, Kazlauskaite R, Dugan SA. Testosterone and visceral fat in midlife women: the Study of Women's Health Across the Nation (SWAN) fat patterning study. Obesity (Silver Spring). 2010;18 3:604-10. doi:https:// doi.org/10.1038/oby.2009.2512009.251.

29. Tsai EC, Boyko EJ, Leonetti DL, Fujimoto WY. Low serum testosterone level as a predictor of increased visceral fat in Japanese-American men. Int J Obes Relat Metab Disord. 2000;24(4):485-91.

30. Nardozza Junior A, Szelbracikowski Sdos S, Nardi AC, Almeida JC. Agerelated testosterone decline in a Brazilian cohort of healthy military men. Int Braz J Urol. 2011;37 5:591-7. doi:https://doi.org/10.1590/s1677-55382011 000500004.

31. Rotter I, Ryl A, Grzesiak K, Szylinska A, Pawlukowska W, Lubkowska A, et al. Cross-Sectional Inverse Associations of Obesity and Fat Accumulation Indicators with Testosterone in Non-Diabetic Aging Men. Int J Environ Res Public Health. 2018;15 6. https://doi.org/10.3390/ijerph15061207.

32. Liao PW, Wu CC, Chen KC, Jaw FS, Yu HJ, Liu SP, et al. Testosterone Threshold for Increased Cardiovascular Risk in Middle-Aged and Elderly Men: A Locally Weighted Regression Analysis. J Sex Med. 2016;13 12:187280. doi:https://doi.org/10.1016/j.jsxm.2016.10.0022016.10.002.

33. Corona G, Bianchini S, Sforza A, Vignozzi L, Maggi M. Hypogonadism as a possible link between metabolic diseases and erectile dysfunction in aging men. Hormones (Athens). 2015;14(4):569-78. doi:https://doi.org/10.14310/ horm.2002.16352002.1635.

34. Hak AE, Witteman JC, de Jong FH, Geerlings MI, Hofman A, Pols HA. Low levels of endogenous androgens increase the risk of atherosclerosis in elderly men: the Rotterdam study. J Clin Endocrinol Metab. 2002;87 8:36329. doi:https://doi.org/10.1210/jcem.87.8.8762.

35. Hougaku H, Fleg JL, Najjar SS, Lakatta EG, Harman SM, Blackman MR, et al. Relationship between androgenic hormones and arterial stiffness, based on longitudinal hormone measurements. Am J Physiol Endocrinol Metab. 2006; 290(2):E234-42. doi:https://doi.org/10.1152/ajpendo.00059.20052005.

36. Corona G, Rastrelli G, Di Pasquale G, Sforza A, Mannucci E, Maggi M. Endogenous Testosterone Levels and Cardiovascular Risk: Meta-Analysis of Observational Studies. J Sex Med. 2018;15 9:1260-71. doi:https://doi.org/10.1 016/j.jsxm.2018.06.0122018.06.012.

37. Ruige JB, Mahmoud AM, De Bacquer D, Kaufman JM. Endogenous testosterone and cardiovascular disease in healthy men: a meta-analysis. Heart. 2011;97 11:870-5. doi:https://doi.org/10.1136/hrt.2010.2107572010.21 0757

38. Araujo AB, Dixon JM, Suarez EA, Murad MH, Guey LT, Wittert GA. Clinical review: Endogenous testosterone and mortality in men: a systematic review and meta-analysis. J Clin Endocrinol Metab. 2011;96 10:3007-19. doi:https:// doi.org/10.1210/jc.2011-11372011-1137.

39. Gibson $\mathrm{CL}$, Attwood L. The impact of gender on stroke pathology and treatment. Neurosci Biobehav Rev. 2016;67:119-24. doi:https://doi.org/10.101 6/j.neubiorev.2015.08.0202015.08.020.

40. Herson PS, Palmateer J, Hurn PD. Biological sex and mechanisms of ischemic brain injury. Transl Stroke Res. 2013;4 4:413-9. doi:https://doi.org/1 0.1007/s12975-012-0238-X.

41. Olsen TS, Andersen KK. Female survival advantage relates to male inferiority rather than female superiority: A hypothesis based on the impact of age and stroke severity on 1-week to 1-year case fatality in 40,155 men and women. Gend Med. 2010;7 4:284-95. doi:https://doi.org/10.1016/.genm.201 0.08.0012010.08.001.

42. Hollander M, Hak AE, Koudstaal PJ, Bots ML, Grobbee DE, Hofman A, et al, Comparison between measures of atherosclerosis and risk of stroke: the 
Rotterdam Study. Stroke. 2003;34 10:2367-72. doi:https://doi.org/10.1161/01. STR.0000091393.32060.0E

43. Jeppesen LL, Jorgensen HS, Nakayama H, Raaschou HO, Olsen TS, Winther K. Decreased serum testosterone in men with acute ischemic stroke. Arterioscler Thromb Vasc Biol. 1996;16 6:749-54. doi:https://doi.org/10.1161/ 01.atv.16.6.749.

44. Yeap BB, Alfonso H, Chubb SA, Hankey GJ, Handelsman DJ, Golledge J, et al. In older men, higher plasma testosterone or dihydrotestosterone is an independent predictor for reduced incidence of stroke but not myocardial infarction. J Clin Endocrinol Metab. 2014;99 12:4565-73. doi:https://doi.org/1 0.1210/jc.2014-26642014-2664.

45. Abi-Ghanem C, Robison LS, Zuloaga KL. Androgens' effects on cerebrovascular function in health and disease. Biol Sex Differ. 2020;11 1:35. doi:https://doi.org/10.1186/s13293-020-00309-4.

46. Tam NN, Gao Y, Leung YK, Ho SM. Androgenic regulation of oxidative stress in the rat prostate: involvement of $\mathrm{NAD}(\mathrm{P}) \mathrm{H}$ oxidases and antioxidant defense machinery during prostatic involution and regrowth. Am J Pathol. 2003;163 6:2513-22. doi:https://doi.org/10.1016/S0002-9440(10)63606-1.

47. Arnlov J, Pencina MJ, Amin S, Nam BH, Benjamin EJ, Murabito JM, et al. Endogenous sex hormones and cardiovascular disease incidence in men. Ann Intern Med. 2006;145 3:176-84. doi:https://doi.org/10.7326/0003-481 9-145-3-200608010-00005.

48. Ohlsson C, Barrett-Connor E, Bhasin S, Orwoll E, Labrie F, Karlsson MK, et al. High serum testosterone is associated with reduced risk of cardiovascular events in elderly men. The MrOS (Osteoporotic Fractures in Men) study in Sweden. J Am Coll Cardiol. 2011;58 16:1674-81. doi:https://doi.org/10.1016/j. jacc.2011.07.0192011.07.019.

49. Shores MM, Biggs ML, Arnold AM, Smith NL, Longstreth WT Jr, Kizer JR, et al. Testosterone, dihydrotestosterone, and incident cardiovascular disease and mortality in the cardiovascular health study. I Clin Endocrinol Metab. 2014;99 6:2061-8. doi:https://doi.org/10.1210/jc.2013-35762013-3576.

50. Holmegard HN, Nordestgaard BG, Jensen GB, Tybjaerg-Hansen A, Benn M. Sex Hormones and Ischemic Stroke: A Prospective Cohort Study and MetaAnalyses. J Clin Endocrinol Metab. 2016;101 1:69-78. doi:https://doi.org/1 0.1210/jc.2015-26872015-2687.

51. Jones RD, Hugh Jones T, Channer KS. The influence of testosterone upon vascular reactivity. Eur J Endocrinol. 2004;151 1:29-37. doi:https://doi.org/1 0.1530/eje.0.1510029.

52. Kley HK, Deselaers T, Peerenboom H, Kruskemper HL. Enhanced conversion of androstenedione to estrogens in obese males. J Clin Endocrinol Metab. 1980;51 5:1128-32. doi:https://doi.org/10.1210/jcem-51-5-1128.

53. Handelsman DJ, Newman JD, Jimenez M, McLachlan R, Sartorius G, Jones GR. Performance of direct estradiol immunoassays with human male serum samples. Clin Chem. 2014;60 3:510-7. doi:https://doi.org/10.1373/clinchem.2 013.2133632013.213363.

54. Karim R, Mack WJ, Hodis HN, Roy S, Stanczyk FZ. Influence of age and obesity on serum estradiol, estrone, and sex hormone binding globulin concentrations following oral estrogen administration in postmenopausal women. J Clin Endocrinol Metab. 2009;94 11:4136-43. doi:https://doi.org/1 0.1210/jc.2009-06432009-0643.

55. Lukanova A, Lundin E, Zeleniuch-Jacquotte A, Muti P, Mure A, Rinaldi S, et al. Body mass index, circulating levels of sex-steroid hormones, IGF-I and IGF-binding protein-3: a cross-sectional study in healthy women. Eur J Endocrinol. 2004;150(2):161-71. doi:https://doi.org/10.1530/eje.0.1500161.

56. Rinaldi S, Key TJ, Peeters PH, Lahmann PH, Lukanova A, Dossus L, et al. Anthropometric measures, endogenous sex steroids and breast cancer risk in postmenopausal women: a study within the EPIC cohort. Int J Cancer. 2006;118 11:2832-9. doi:https://doi.org/10.1002/ijc.21730.

57. Glenn T, Harris AL, Lindheim SR. Impact of obesity on male and female reproductive outcomes. Curr Opin Obstet Gynecol. 2019;31 4:201-6. doi: https://doi.org/10.1097/GCO.0000000000000549.

\section{Publisher's Note}

Springer Nature remains neutral with regard to jurisdictional claims in published maps and institutional affiliations.

Ready to submit your research? Choose BMC and benefit from:
- fast, convenient online submission
- thorough peer review by experienced researchers in your field
- rapid publication on acceptance
- support for research data, including large and complex data types
- gold Open Access which fosters wider collaboration and increased citations
- maximum visibility for your research: over 100M website views per year
At BMC, research is always in progress.
Learn more biomedcentral.com/submissions

